\title{
Research on the Application of GA-ELM Model in Carbon Trading Price - An Example of Beijing
}

\author{
Yanmei Li*, Jiawei Song \\ Department of Economic Management, North China Electric Power University, Baoding 071000, China
}

Received: 20 February 2021

Accepted: 1 June 2021

\begin{abstract}
To effectively solve the environmental pollution caused by greenhouse gases, countries around the world have successively set up carbon emission trading markets in recent years. At present, China's carbon trading market is only in its infancy, making various mechanisms and policies insufficient. As the core issue of carbon trading market, the fluctuations of carbon trading price are related to the investment decisions of market participants, the formulation of enterprise production and operation plans, and the realization of global emission reduction targets. Therefore, it is of great practical significance to study the influencing factors of carbon price fluctuations and to predict future carbon prices. In this paper, we take the carbon trading week data of the Beijing carbon trading market in China from May to September 2020 as the research object. Firstly, the gray correlation technique is employed to measure the rationality of the selected factors affecting carbon price fluctuations. Secondly, through the principal component analysis method to analyze the various influencing factors, it is found that energy prices and macroeconomic development are the main factors affecting carbon prices, and weather conditions will also cause carbon price fluctuations. Then, four different models are proposed to predict carbon trading prices, and the forecast results are evaluated through the performance evaluation index system. The results show that the GA-ELM model has the best prognosis effect. Finally, according to the analysis results, it provides a useful theoretical reference for carbon market decision makers and participants.
\end{abstract}

Keywords: carbon trading price, extreme learning machine, genetic algorithm, influencing factor, principal component analysis

\section{Introduction}

While economic development promotes the progress of the times, it has also caused many severe

*e-mail: yanmei.li@ncepu.edu.cn

environmental problems. The most serious problem is the greenhouse effect caused by the emission of polluting gases such as carbon dioxide, which greatly threatens the ecological balance and people's quality of life. How to ensure that emissions are effectively reduced while improving the environment without affecting economic development has become the focus of attention of all countries in the world. This is 
a responsibility that all countries should bear. To address this problem, the European Union set up the European Union Emissions Trading System (EU ETS) in January 2005. This is the world's first carbon emissions trading system and is currently the world's largest carbon market [1-2]. The target product is the European Union Emissions Allowance (EUA). Under this system, carbon exchanges have gradually been established around the world. From the perspective of emission reduction effects, the carbon trading market takes carbon emission allowances as a commodity, and forms a reasonable carbon trading price through the supply and demand mechanism. So as to availably control and reduce greenhouse gas emissions, and guide enterprises to make correct emission reduction decisions. This mechanism is increasingly significant for curbing global carbon emissions.

As a major carbon emitter and a main international supplier of CERs, China has also taken a series of measures to reduce greenhouse gas emissions. Since 2013, China has opened eight carbon trading markets in Beijing, Shanghai, Tianjin, Guangzhou, Shenzhen, Chongqing, Hubei and Fujian. It has also formulated many policies for energy conservation and emission reduction, and improved relevant laws and regulations [3-5]. In recent years, carbon trading has become increasingly active, which shows that China's carbon emissions trading has a certain scale and the carbon market has broad prospects. However, due to the relatively short establishment of the carbon market, which is an emerging market, there are still some problems. For example, relatively small transaction volume, simplification of carbon financial products, insufficient enthusiasm of enterprises to participate in the carbon market, insufficient market effectiveness, etc., which are closely related to the lack of a complete carbon price research mechanism.

Therefore, it is very crucial to study the influencing factors of price fluctuation in China's carbon market and forecast the future carbon price, which can not only enable investors to avoid the risk of carbon price, but also help enterprises to deeply understand the law of price fluctuation in the carbon market, so as to make production and operation decisions. More importantly, it is related to the development and improvement of China's carbon trading market, which is conducive to establishing a stable carbon market price mechanism and related laws and regulations, effectively promoting the realization of emission reduction targets, and thus enhancing China's voice in the global carbon market.

Since the establishment of the carbon emission trading market, domestic and foreign scholars have explored it from different entry points, including the influencing factors of carbon emissions [6-7], the fluctuation characteristics of transaction prices [810], and market transaction mechanisms [11-14]. The study of carbon price mechanism by foreign scholars can be divided into the following two aspects. On the one hand, it discusses the model of price mechanism theoretically [15-17]; on the other hand, it conducts empirical research on European emission trading as the research object [18-19]. Some academics have also proposed that the socio-economic and financial markets will also affect the fluctuation of carbon prices [2024]. Moreover, Mehmet Cetin mainly analyzed the relationship between weather factors (such as wind speed, temperature, humidity, and seasonal conditions) and carbon dioxide content from the micro-level [2527]. From a macro perspective, changes in emissions will also affect the trading of carbon allowances, indirectly causing price fluctuations.

Due to the late formation of China's carbon emission rights trading market, domestic scholars' research on carbon emission rights is still at a preliminary stage. Chen et al. [28] shows through empirical research that compared with other influencing factors, coal prices are the main factor affecting carbon prices. Wang et al. [29] studied the influencing factors of carbon price based on the EEMD method and the FGLS method. The results showed that the price of carbon emission rights is closely related to the price of energy, of which oil price is the most important factor affecting the fluctuation of carbon price. In addition, factors such as GDP growth rate and temperature in various regions have different effects on carbon prices. Zhao et al. [30] applied a structural equation model to probe the influencing factors of carbon prices. The results showed that in addition to market environment factors, policy factors will also have a greater impact on the fluctuation of carbon trading prices. Feng et al. [31] analyzed the market risk of EU ETS carbon price based on the CAPM model. The results show that the conclusion of international negotiations will impact the carbon price by affecting the carbon emission limit and the size of the carbon market capacity. Gao et al. [32] used wavelet analysis and VAR model to study the operation mechanism and price fluctuation law of EU carbon market, and found that the main factor affecting the development expectation of carbon trading market is the international macroeconomic situation.

Scholars at home and abroad have used various methods to analyze the different influencing factors of carbon trading prices in detail. The main influencing factors include energy prices, social economy, weather conditions, carbon market structure, etc. Although scholars have relatively complete research on influencing factors, they lack a comprehensive analysis of the influencing factors of carbon prices. Therefore, we will combine existing literature and comprehensively consider the degree of influence of various factors on carbon trading prices.

The international research on carbon financial product price prediction started earlier, mainly applying GARCH, ARMA and other methods [33-40]. Traditional forecasting methods such as GARCH can better explain the relationship between variables and between variables and results, but the forecasting accuracy is low and needs a large number of data samples as support. 
In fact, such models may not provide enough flexibility to correctly model the characteristics of dynamic carbon price fluctuations. In recent years, scholars are more inclined to adopt intelligent algorithms, such as traditional neural network method, wavelet analysis method, support vector machine. In addition, they also adopt the model combining optimization algorithms such as fruit fly optimization, genetic optimization and intelligent algorithm to apply in the field of carbon price prediction.

Tsai et al. [41] resorted the RBFNN to project the carbon price of the EU market with coal prices, oil prices, and natural gas prices as input variables. It demonstrated that the RBFNN model performed a better prediction effect. Li et al. [42] combined the EMD model and the GARCH model to predict the carbon trading price of 5 pilot provinces and cities in China after 2016. Cui et al. [43] decomposed the carbon price according to the empirical mode decomposition algorithm, using EMD-GA-BP model, EMD-PSO-LSSVM model to predict domestic carbon price from three aspects (international carbon price, domestic and foreign energy market and domestic economy). Zhang et al. [44] used the ensemble empirical mode decomposition to decompose the error alignment predicted by the BPNN. The outcome manifested that the error correction can optimize the prediction accuracy of the international carbon market price affected by multiple factors. In addition, some researched adopted swarm intelligence algorithms to optimize the neural network carbon price prediction model. Zhu et al. [45] used group method of data handling(GMDH) to select the lag period price that had the most impact on the present carbon price, and applied particle swarm optimization (PSO) to optimize.

It can be seen from previous studies that back propagation and other traditional neural network or SVM methods are often selected to investigate carbon price. The convergence rate of $\mathrm{BP}$ and other traditional neural network learning algorithms is slow, and it is prone to problems such as local optimization and overfitting. Although SVM can overcome the problem, and the optimization of SVM parameters by cross validation and particle swarm optimization can improve the prediction accuracy, its program running speed is slow.

Therefore, a prediction method for carbon trading price based on an Extreme learning machine model optimized by genetic algorithm has been proposed. This method comprehensively considers energy prices, macroeconomics, weather and other influencing factors, and conforms to the actual conditions of price forecasts. Moreover, the genetic algorithm is used to optimize the weight and threshold of the hidden layer, which effectively solves the problems of local optimization, over-fitting, and slow running speed.

According to the existing literature, this paper selects 10 factors that have influence on the fluctuation of carbon price. Firstly, the applicability of the selected factors is confirmed by grey correlation technology. Secondly, the principal component analysis method is used to explore these 10 influencing factors, and the common factors with high information retention rate are extracted. Then, taking the influencing factors as the input data of GA-ELM model, taking the weekly data from May to August in 2020 as the training set and the weekly data from September in 2020 as the test set, the weekly carbon price in September in 2020 is predicted. Finally, the prediction results are evaluated by the index system.

Compared with existing studies, this paper makes the following contributions on energy policy:

1) Few scholars have used the GA-ELM model in terms of carbon trading price projections. Consequently, this thesis will apply the GA-ELM model to calculate the carbon price.

2) Principal component analysis is adopted to reel common factors, which could effectively retain most of the information of the index and reflect the main factors affecting the fluctuation of carbon price.

3) During the modeling process, the historical price is used as the training set, and the prediction period is used as the test set. In addition to considering energy price factors and macroeconomic factors, weather conditions are also introduced into the model as the input layer of the GA-ELM model, making it more comprehensive and accurate.

4) Comparing the GA-ELM model with other traditional models (BP, ELM, GA-BP), GA-ELM model significantly improves the accuracy of carbon price prediction and has a better prediction effect.

This paper is organized as follows: Section 2 introduces the data explanation and theoretical basis of this article. Section 3 mainly focuses on building models and related analysis. Section 4 summarizes the research content and puts forward reasonable suggestions.

\section{Materials and Methods}

\section{Materials}

In this article, the Beijing carbon trading market from May 2020 to September 2020 carbon price weekly data is selected as the research object. According to the existing domestic and foreign literature, the factors that influence the price of carbon trading include energy prices, macroeconomic indicators, and weather conditions. The relevant data of the influencing factors is also the weekly data during the study period. This is a total of 22 weeks.

1) Carbon trading price. The research sample is the data from the Beijing carbon trading market, excluding weekends and holidays, weighting the carbon trading volume on the effective trading day of each week to obtain the weekly price of carbon trading. Carbon trading day data comes from Beijing Environment Exchange. 
2) Energy price. Coal, oil, and natural gas are the three main sources of energy consumption in China. Among them, coal accounts for the largest proportion, and oil mainly relies on imports. Therefore, the weekly data of Brent crude oil CFD, Bohai-rim steam-coal price index, and natural gas market quotes are selected to represent energy prices. The data are from https:// finance.sina.com.cn/, WWW.CQCOAL.COM, and cngold.org respectively.

3) Macroeconomic indicators. Macroeconomic conditions, especially industrial economic development, can best represent carbon dioxide emissions, which in turn will affect carbon trading price. This article selects indicators that reflect the status of domestic and foreign industrial development and economic development, including weekly data from SSE Industrial Index, the Dow Jones Industrial Average, S\&P 500 Index, and CSI 300 Index. The data are from Investing.com and cngold. org respectively.

4) Weather conditions. The air quality index is an indicator that reflects the situation of haze and air pollution. Generally speaking, the more waste gas emitted by industries, the worse the air quality. The proportion of carbon dioxide in the waste gas cannot be underestimated. Therefore, in addition to selecting weekly data of temperature and wind speed, the air quality index is also included in the range of influencing factors. The data comes from the weather network.

\section{Methods}

\section{Principal Components Analysis}

The principal component analysis method is a multivariate statistical analysis method that obtains several principal component indexes after linear transformation of multiple indexes. In practical problems, we often encounter multiple indicators (variables). Under normal circumstances, there will be a certain correlation between different indicators, which increases the complexity of problem analysis. The Principal Component Analysis (PCA) is to recombine multiple indexes with correlation to obtain a group of comprehensive indexes without correlation. These comprehensive indicators should retain as much information as possible from the original indicators. This is an effective way to reduce dimensionality in mathematics.

Assuming there are $p$ indicators, these indicators have a certain degree of correlation. We need to use the method of linear combination to recombine the $p$ indicators into a group of independent comprehensive indicators to replace the original indicators. Marking the first comprehensive indicator selected as $F_{1}$, and the comprehensive indicator should retain as much information of the original indicator as possible. The variance of $F_{1}$ is the criterion for the amount of information retained. The larger the variance, the more information this comprehensive indicator contains.
Generally, $F_{1}$ has the largest variance, which is called the first principal component, and then the second comprehensive index can be selected. According to the requirements of principal component analysis, the information contained in $F_{1}$ does not need to be reflected in $F_{2}$ again ( $F_{2}$ is the second principal component). Following the same procedure, the third, fourth, ..., $m$ principal components $(m \leq p)$ can be extracted. These $m$ principal components are not correlated with each other and the variance is decreasing. Generally, the principal component is required to retain more than $85 \%$ of the information. Although this will cause the loss of some information, this method allows us to grasp the main contradiction and obtain some new information. When solving practical problems, this can actually improve the efficiency and accuracy of handling problems.

\section{Genetic Algorithm}

Genetic algorithm is a randomized search algorithm established based on the natural laws and genetic mechanisms of the biological world. This method simulates the reproduction, crossover and gene mutation phenomena of organisms in the process of natural selection and heredity. In each generation, the next set of candidate solutions will be retained, and some better individuals will be selected from the population based on a certain index. These individuals are recombined through the three genetic operators to produce a new generation of candidate populations. This iteration continues until a certain convergent index is met. The algorithm flow is shown in Fig. 1.

\section{Extreme Learning Machine}

Extreme learning machine is an algorithm for single hidden layer feedforward neural network [46]. Compared with traditional feedforward neural networks, this algorithm improves the training speed of the model and obtains the global optimal solution. The ELM model can randomly generate the connection weights of the input layer and the hidden layer and the threshold of the hidden layer neurons. Once determined, the whole process only needs to determine the number of neurons in the hidden layer, other parameters remain unchanged, and then the unique optimal solution can be obtained. The structure of the algorithm is shown in Fig. 2, which consists of an input layer, a hidden layer and an output layer. The neurons in each layer are fully connected.

Specifically, the ELM algorithm mainly includes the following five steps:

1) Determine the number of neurons in the hidden layer;

2) Randomly set the connection weight $w$ the threshold $b$;

3) Choose an activation function. The most commonly used is the sigmoid function;

4) Calculate the output matrix of the hidden layer; 


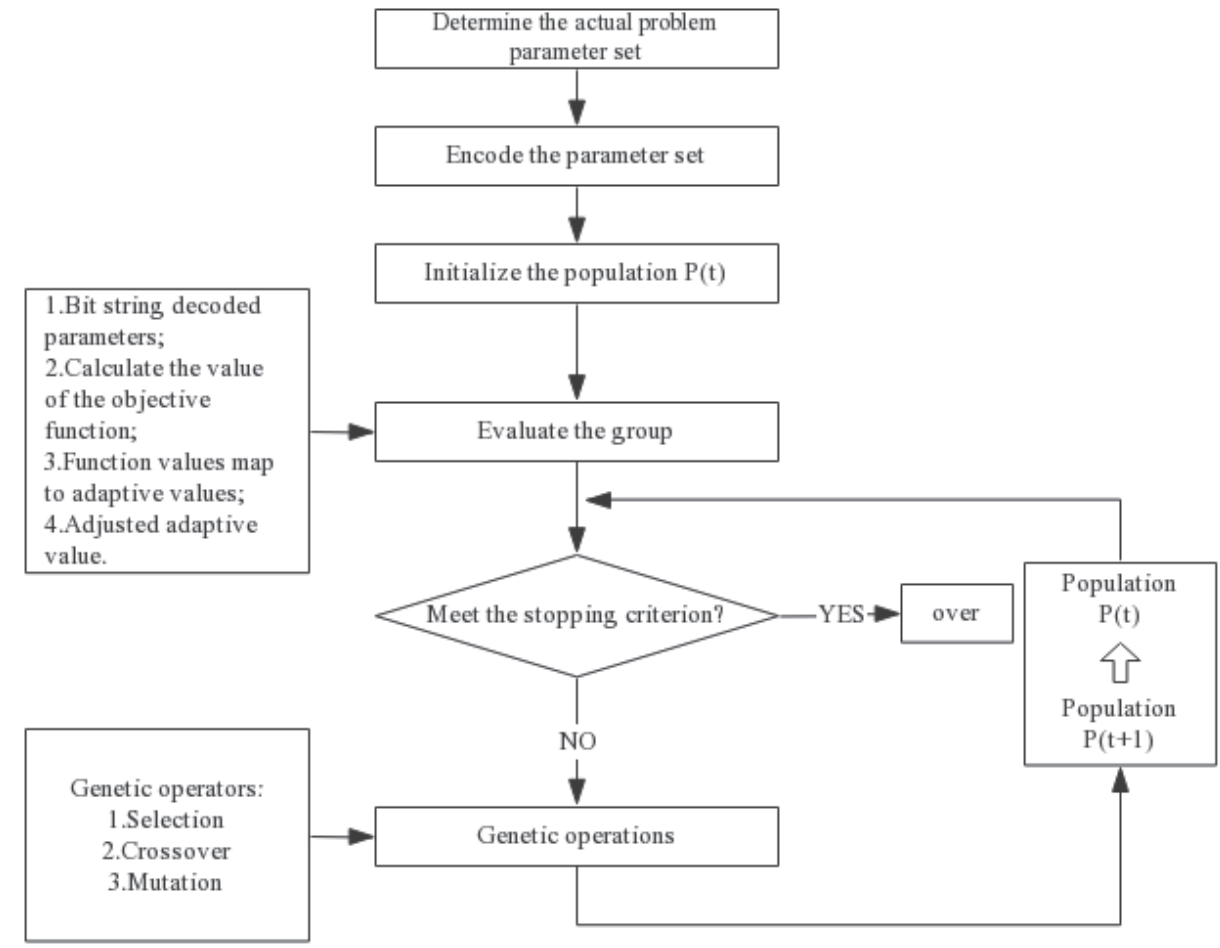

Fig. 1. Basic flow chart of genetic algorithm.

5) Use the least square method to calculate the minimum output layer weight.

Up to present, ELM model have been applied to various regression and classification problems, and many improved ELM algorithms have also appeared to solve specific problems [47-51].

\section{GA-ELM Model}

According to the description of ELM algorithm, the connection weight and threshold are generated randomly, which may lead to the absence of the inverse matrix of the output matrix of the hidden layer. This results in the problem that some hidden layer nodes are invalid, which reduces the reliability and accuracy of ELM model prediction. To solve it, a genetic algorithm is proposed to optimize and screen the connection weights and thresholds between the input layer and the hidden layer, which ensures that the output matrix has a generalized inverse matrix. In this way, the learning speed, accuracy and overall robustness of the model are improved to some extent. The specific operation steps are as follows:

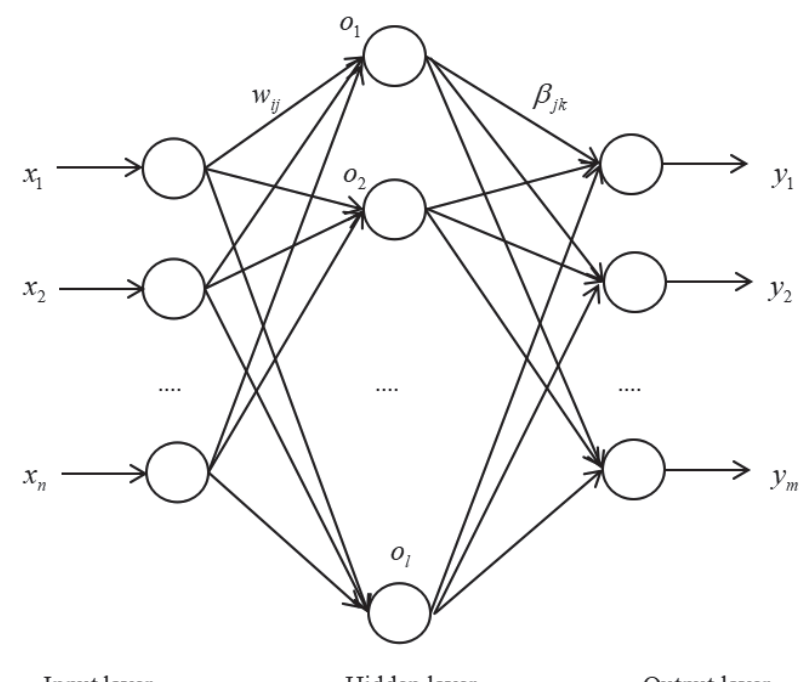

Fig. 2. Framework of ELM. 
1) Take data of carbon price and its influencing factors as training samples of input layer;

2) Establish an ELM neural network according to the input samples;

3) Define the population number of genetic algorithm and the optimization goal to be achieved;

4) Encode connection weights and thresholds;

5) Train the population to get the individual's adaptability;

6) According to the fitness calculation results, run genetic operators (selection, crossover, mutation) to obtain subpopulations;

7) Judge whether the condition for ending the cycle is reached. If it is met, proceed to the next step; if the condition is not met, return to the fifth step. The end condition is to reach the set optimization goal or the maximum number of iterations;

8) The GA-ELM model is updated according to the optimized connection weights and thresholds;

9) Input the influencing factor data into the prediction model, and finally calculate the result.

Fig. 3 shows the flow chart of this method.

\section{Results and Discussion}

Inquiry of Influencing Factors

This paper selects ten carbon price influencing factors in line with the existing literature, so it has a certain degree of subjectivity and randomness. In view of this, this section first needs to test whether the selected ten influencing factors are related to carbon price, that is, whether these factors have an effect on carbon price fluctuations. Then we will analyze in depth which factors are the main factors that affect the fluctuation of carbon price, so as to predict the carbon price later.

\section{Grey Relation Analysis}

Due to the immature development of China's carbon trading market, with limited statistical data and large gray scales, traditional measurement methods have certain limitations in processing these data. Intentionally, this paper chooses the most commonly

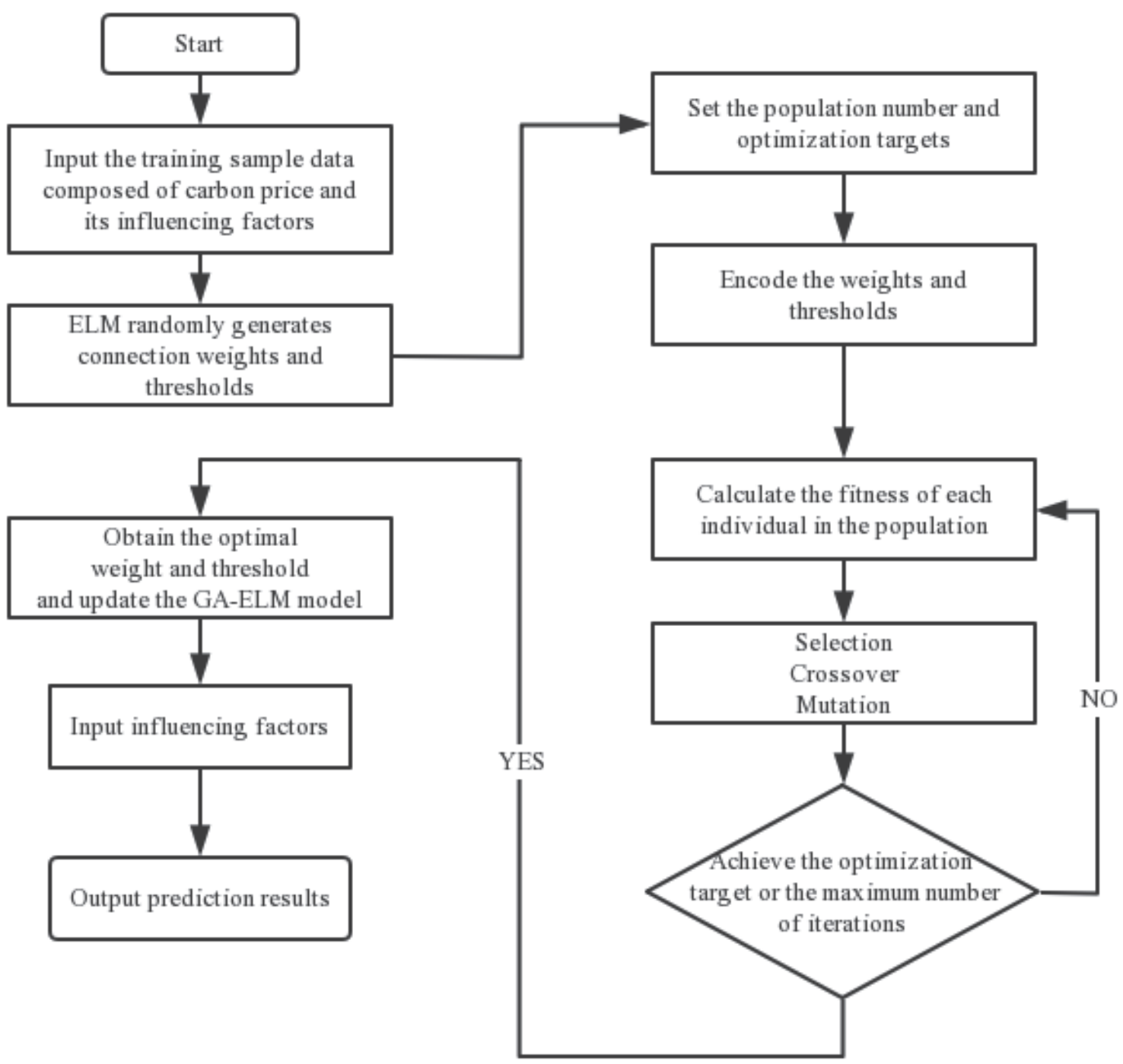

Fig. 3. Flowchart of the GA-ELM model. 
used grey correlation coefficient when analyzing the influencing factors, which is based on the degree of similarity or difference between the development trends of different data series to measure the closeness between factors.

Assuming that $X_{0}(k)(k=1,2, \ldots, 22)$ represents the carbon emission price in 22 weeks, $X_{i}(k)(i=1,2, \ldots, 10)$; $k=1,2, \ldots, 22)$ is the selected ten influencing factors. $X_{0}(k)$ and $X_{i}(k)$ have the same length. Before calculating the correlation coefficient, it is first necessary to normalize the data to eliminate the dimension, and then calculate the gray correlation coefficient according to equation (1). Among them, the smaller the resolution coefficient $\rho$, the greater the degree of discrimination. Generally, the value of 0.5 is more appropriate. Finally, the correlation sequence is obtained by averaging the correlation coefficient.

$\zeta_{i}(k)=\frac{\min _{i} \min _{k}\left|x_{0}(k)-x_{i}(k)\right|+\rho \cdot \max _{i} \max _{k}\left|x_{0}(k)-x_{i}(k)\right|}{\left|x_{0}(k)-x_{i}(k)\right|+\rho \cdot \max _{i} \max _{k}\left|x_{0}(k)-x_{i}(k)\right|}$

Table 1 displays the grey relation degree between carbon price and various influencing elements. Overall, the correlation is relatively high the results are all greater than 0.5 . It proves that the influencing factors adopted in this paper are reliable and can be employed as a basis for building a model.

Bohai-Rim Steam-Coal Price Index and carbon price have the greatest relationship. China is a coalbased energy structure, which is the direct driving force for the development of China's pillar industries. The consumption of this type of energy is directly related to carbon dioxide emissions, thereby affecting the fluctuation of carbon prices in the market. The order of correlation degree of each influencing factor on carbon emission trading price is Bohai-Rim Steam-Coal Price Index $>$ CSI 300 Index $>$ SSE Industrial Index $>$ Dow Jones Industrial Average $>$ S\&P 500 Index $>$ Natural Gas Price $>$ Wind Speed $>$ Air Quality Index $>$ Brent Crude Oil CFD $>$ Temperature.

\section{Results of Principal Components Analysis}

According to the analysis results of the relationship between the above-mentioned influencing factors and carbon prices. It shows that each factor will have varying degrees of impact on carbon prices. However, it is necessary to find the main factors affecting carbon price from the selected ten factors and reduce the correlation between the various factors, which is conducive to accurate prediction of future carbon prices. Therefore, this article uses principal component analysis to probe ten factors.

In the light of the correlation coefficient matrix of each variable, it can be found that the selected factors have a strong correlation. For example, the correlation coefficients between Brent crude oil CFD and Bohai-
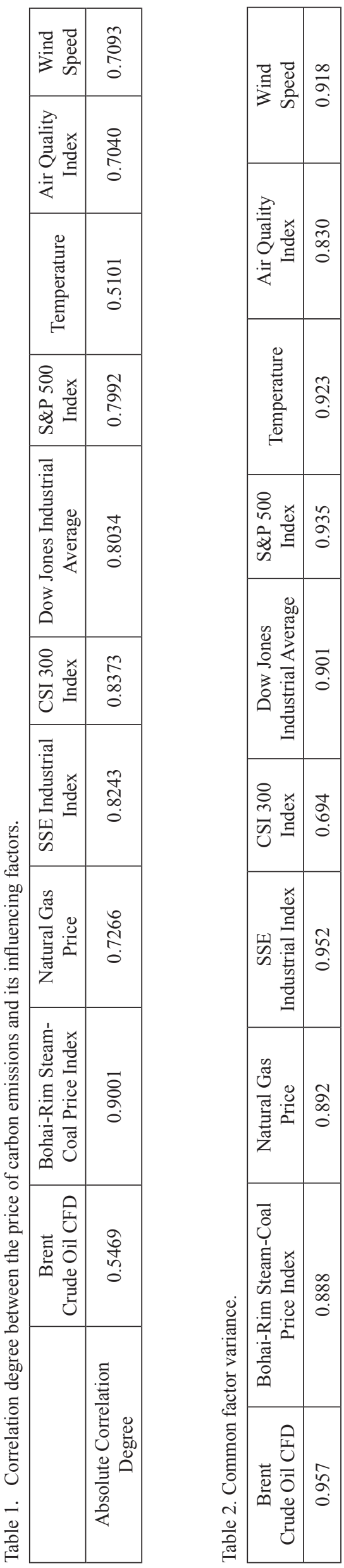
rim steam-coal price index, Natural gas market quotes, SSE industrial index, Dow Jones industrial average, S\&P 500 index are relatively large, which indicates that there is overlap between these indexes.

Generally speaking, when the KMO result is greater than 0.5 , it indicates that there is a correlation between the variables. The closer the value is to 1 , the more suitable for principal component analysis. In addition, when the significance of Bartlett's test is less than 0.5, it is applicable for principal component analysis. The calculation results show that the KMO value is 0.768 , and the Sig value of Bartlett's test is 0.000 , which confirms that the principal component analysis can be carried out in this paper and the applied method is rational.

It can be seen from the calculation results of the total variance contribution of each factor that when the number of common factors reaches three, as the number of common factors increases, the eigenvalue decreases gradually. Besides, when the number of common factors is three, the cumulative variance contribution rate of eigenvalues has reached $88.891 \%$. The value is close to $90 \%$, indicating that the extracted principal components have retained as much index information as possible and are within a reasonable interpretation range. The other ingredients contain less information, so they are discarded. Therefore, the number of common factors is set as three, denoted as $F_{1}, F_{2}$ and $F_{3}$ respectively.

When the common factor variance is greater than 0.5 or 0.7 , it can indicate that the variable can be expressed by the extracted common factor. As can be seen from Table 2, the common variance values of the ten influencing factors selected in this paper are generally above 0.8 , and only the CSI 300 index has a smaller corresponding value of 0.694 . But on the whole, the ten indicators selected can be successfully expressed by common factors.

Table 3 is the Component Matrix, where the calculated value represents the correlation coefficient between the extracted common factor and each variable. From the perspective of the absolute value of the result, the larger the value, the closer the relationship between the two, and the more indicator information the common factor represents. It can be seen from the Table 3 that:

- Brent crude oil CFD, Bohai-rim steam-coal price index, Natural gas price, SSE Industrial Index, CSI 300 Index, Dow Jones industrial average, S\&P 500 Index, and Air quality index have higher loads on the first principal component, and their values are more than 0.7 , indicating that there is a strong correlation between the first principal component and each variable, which is a comprehensive performance of these indicators. Therefore, the first principal component mainly reflects the impact of energy prices and macroeconomic conditions on the fluctuation of carbon trading prices. In addition, it can be known from the total variance contribution of each factor that the first principal component already
Table 3. Component matrix.

\begin{tabular}{|c|c|c|c|}
\hline & $F_{1}$ & $F_{2}$ & $F_{3}$ \\
\hline $\begin{array}{c}\text { Brent Crude Oil CFD } \\
\text { Bohai-Rim Steam-Coal Price } \\
\text { Index }\end{array}$ & 0.885 & 0.394 & 0.136 \\
\hline Natural Gas Price & -0.907 & -0.262 & -0.017 \\
\hline SSE Industrial Index & 0.949 & -0.224 & -0.022 \\
\hline CSI 300 Index & -0.764 & 0.012 & 0.331 \\
\hline Dow Jones Industrial Average & 0.948 & 0.036 & -0.011 \\
\hline S\&P 500 Index & 0.965 & -0.052 & 0.045 \\
\hline Temperature & 0.246 & 0.915 & 0.155 \\
\hline Air Quality Index & -0.722 & 0.315 & 0.458 \\
\hline Wind Speed & -0.389 & 0.431 & -0.762 \\
\hline
\end{tabular}

contains almost $65 \%$ of the index information, which means that energy prices and macroeconomic factors are the dominant factors that cause carbon price fluctuations.

- Temperature has a high load on the second principal component, whose value is as high as 0.915 . The second principal component mainly reflects the effect of temperature on carbon price.

- The load factor of wind speed on the third principal component is 0.762 . This principal component mainly reflects the influence of wind speed on carbon price. The three principal components reflect different information.

Finally, the requirement for the extracted principal components is that the principal components are not related to each other. The calculation results of the covariance matrix of the three principal components show that there is no correlation between the principal components. In summary, the three principal components extracted are reasonable.

\section{Empirical Analysis of Carbon Price Prediction}

\section{Parameter Settings and Error Evaluation Indexs}

\section{1) Parameter settings}

In order to improve learning accuracy, we set the number of hidden layer neuron nodes equal to the number of training set samples, both of which are 17 . So as to preserve population information and better offspring genetics, the number of populations should not be set too small. Thence, we install the number of populations to 20 , the maximum genetic algebra to 100 , and the number of training sessions to 2000. The most commonly used sigmoid activation function is selected.

2) Error evaluation indexes

It is indispensable to display the forecasting effects of different algorithms by constructing relevant index systems. This study utilizes four generally recognized 
prediction evaluation criteria to judge the prediction results of each models, including the Mean Absolute Error (MAE) that better reflects the reality of the forecast error, the Mean Absolute Percentage Error (MAPE) error to count the error value, the Root Mean Squared Error (RMSE) used as a measure of the accuracy of machine learning prediction results and $\mathrm{R}^{2}$. The calculation formula of each index is as follows:

$$
\begin{gathered}
M A E=\frac{1}{N} \sum_{i=1}^{N}\left|y_{i}-\hat{y}_{i}\right| \\
M A P E=\left(\frac{1}{N} \sum_{i=1}^{N} \frac{\left|y_{i}-\hat{y}_{i}\right|}{y_{i}}\right) \times 100 \% \\
R M S E=\sqrt{\frac{1}{N} \sum_{i=1}^{N}\left(y_{i}-\hat{y}_{i}\right)^{2}} \\
R^{2}=1-\frac{\sum_{i=1}^{N}\left(y_{i}-\hat{y}_{i}\right)^{2}}{\sum_{i=1}^{N}\left(y_{i}-\bar{y}_{i}\right)^{2}}
\end{gathered}
$$

In the equation: $y_{i}$ is the actual value of the test current price of carbon, $\bar{y}_{i}$ refers to the average of the true value, and $\hat{y}_{i}$ represents the prognosis result of carbon price.

MAE represents the actual status of the predicted value error, MAPE can reflect the precision of the predicted value, and RMSE embodies the degree of dispersion and stability of the result. These three indicators are all error indicators, and their range is $[0$, $+\infty)$. When the predicted value is completely consistent with the true value, it is a perfect model, which is difficult to realize in practice. If the index value is smaller, which means the error is smaller, then the model prediction effect is better. The larger the value of $\mathrm{R}^{2}$, the more consistent the predicted value and the true value, the better the prediction effect.

\section{Comparing Prediction Results of Various Models}

Fig. 4 is the prediction result of the weekly carbon emission price data of the Beijing carbon trading market in September 2020 based on four algorithms. It can be seen intuitively from the prediction curve that the prediction result curve of the GA-ELM model is the most consistent with the actual value. The ELM curve has the largest fluctuation range, and the output effects of the other two algorithms are moderate.

In order to be able to further analyze the prediction performance of the model, Table 4 shows the prediction values and evaluation index calculation results of various algorithms. The conclusions are as follows:

- The Mean Absolute Error (MAE) of the predicted value of the GA-ELM algorithm is the lowest, only 0.51634 , which is a very considerable number. It indicates that the error between the actual value and the predicted value is the smallest. The mean absolute error value of the other three models are 3.56182 (BP), 3.90679 (ELM) and 3.62376 (GA-BP), respectively. The MAE values of them is 7-8 times that of the GA-ELM model;

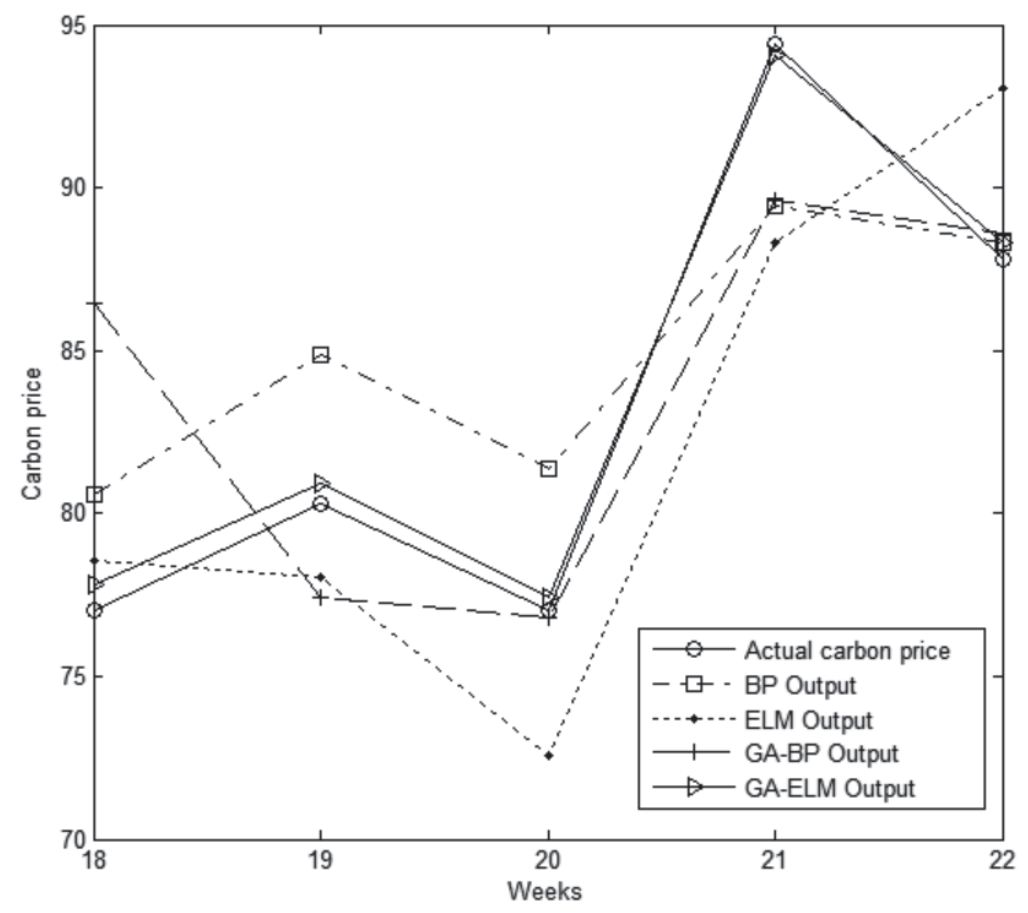

Fig. 4. Comparison chart of carbon price prediction results of different algorithms. 
Table 4. Carbon price prediction results and error analysis of different algorithms.

\begin{tabular}{|c|c|c|c|c|c|}
\hline & Desired Value & BP Output & ELM Output & GA-BP Output & GA-ELM Output \\
\hline 18 & 77.0472 & 80.5606 & 78.5764 & 86.4264 & 77.8379 \\
\hline 19 & 80.2999 & 84.8507 & 78.0620 & 77.4255 & 80.9027 \\
\hline 20 & 77.0472 & 81.3507 & 72.5924 & 76.7822 & 77.435 \\
\hline 21 & 94.3975 & 89.426 & 88.2981 & 89.5965 & 94.0825 \\
\hline 22 & 87.8224 & 88.2923 & 93.0350 & 88.6215 & 88.3078 \\
\hline MAE & - & 3.56182 & 3.90679 & 3.62376 & 0.51634 \\
\hline MAPE $(\%)$ & - & 4.32289 & 4.59009 & 4.41856 & 0.63333 \\
\hline RMSE & - & 3.91179 & 4.27941 & 4.89878 & 0.54292 \\
\hline $\mathrm{R}^{2}$ & - & 0.66850 & 0.60326 & 0.48011 & 0.99361 \\
\hline
\end{tabular}

- According to the Mean Absolute Percentage Error (MAPE), the prediction accuracy of GA-ELM model is also the highest, as high as $0.63333 \%$. The accuracy of the prediction results of other models is also relatively high, with a prediction accuracy level of $4.3 \%$ to $4.6 \%$. But it is obviously not as accurate as the GA-ELM model;

- The Root Mean Square Error (RMSE) can reflect the dispersion degree and stability of the prediction model. Apparently, the loss of the GA-ELM prediction model is the smallest;

- In addition, the $\mathrm{R}^{2}$ value of the GA-ELM model is 0.99361 , and the predicted value is very close to the actual value, indicating that the prediction effect is completely satisfactory.

In addition, we also analyze the percentage errors of different models in the prediction period. The GA-BP model has the largest percentage error volatility. Its maximum error value is $12.1734 \%$ in $18^{\text {th }}$ week, and the minimum error is $0.3439 \%$ in $20^{\text {th }}$ week. The percentage errors of BP and ELM algorithms show a trend of increasing first and then decreasing, with a difference of about $5 \%$. The GA-ELM model has the smallest percentage error amplitude and error value. Its error curve is flat and close to the horizontal axis. The error level is between $0.3 \%$ and $1.1 \%$. Among them, the maximum prediction error is the predicted value of the GA-BP model in $18^{\text {th }}$ week, and its percentage error value is $12.1734 \%$. The minimum prediction error is the predicted value of the GA-ELM model in $21^{\text {th }}$ week, and its percentage error value is $0.3334 \%$.

It can be concluded from the empirical analysis consequences that compared with the other three models, the GA-ELM model has the best prediction effect for the carbon emission trading price in Beijing in September 2020. This not only shows that the method is suitable for carbon price prognostication, but means that the analysis and treatment of influencing factors in the previous section are reasonable.

\section{Conclusions}

The research content of this paper is mainly divided into two parts. On the one hand, the principal component analysis method is adopted to probe into the influencing factors of carbon trading prices. On the other hand, using the weekly carbon emissions trading price of the Beijing carbon trading market from May to September 2020 (a total of twenty-two weeks) as a sample, four different algorithms are proffered to predict the Beijing carbon emissions trading price in September 2020 (a total of five weeks). The final conclusions are as follows:

1) Energy prices and macroeconomic development are the main factors affecting carbon prices. Weather conditions, especially the air quality index, will also impact on it. We select the prices of three representative energy sources-oil, coal, and natural gas-as energy price indicators. While the large-scale use of oil and coal can promote the development of industrial economy, the environmental pollution problems brought by it should not be underestimated. To reduce emissions, it is necessary to consider the issue of carbon emission allowances according to the regional or national economic development level and environmental conditions, and to trade carbon emission allowances as a commodity. Thus, large companies with a lot of carbon emissions hope to get more allowances, and companies with less carbon emissions will have spare emissions. The supply and demand relationship of carbon emission quota in the market will cause the fluctuation of carbon trading price;

2) The extreme learning machine model optimized by genetic algorithm has wonderful prediction accuracy and network generalization performance in carbon price prediction, and it is significantly better than the three models of BP, ELM, and GA-BP. The initial connection weight and the threshold could be effectively optimized by genetic algorithm. While considering the historical price in the prediction model, three types of influencing factors-energy price, macroeconomic indicators and 
weather conditions-are also used as the input layer of the model. In this way, it reduces the difficulty of carbon price prediction and improves the accuracy of model prediction. The MAE of the GA-ELM model prediction results is as low as 0.51634 , the MAPE is $0.63333 \%$, and the RMSE is 0.54292 . This is an ideal prediction effect and provides efficacious model assistance for future carbon price predictions;

3) It is of great practical significance to research the influencing factors of carbon prices and make predictions on future prices, which can present theoretical guidance for carbon trading market participants. Based on the research results of this article, the following suggestions are proffered:

- Continue to carry out and implement various emission reduction strategies. In order to deal with environmental problems, China has taken the reduction of carbon intensity as a binding index into its national economic and social development plan, and adopted a series of policies and measures such as optimizing energy structure, saving energy and improving energy efficiency, and actively increasing forest carbon sinks. Not only is it helpful to achieve global emission reduction targets, but it can also promote the transformation of the world economy to a green economy and a sustainable economic situation.

- Give full play to the role of government in the construction of carbon market. The first step to improve the carbon trading market is to strengthen the organic combination between the government and the carbon market. The government needs to accelerate the improvement of relevant laws, regulations and trading systems, promote the formation of carbon derivatives, and rationally arrange corporate carbon emission allowances, so as to promote the smooth operation of the carbon trading market and provide market participants with a healthy trading environment.

- Improve the enthusiasm of market participants. Companies adjust their production and operations based on price information in the carbon market, and they are the main participants in China's carbon trading market. In fact, there are many potential participants in China's carbon market. While encouraging enterprises to reduce emissions, we should also raise people's awareness of reducing emissions, which can not only activate the market and increase the liquidity of carbon assets, but also facilitate the completion of the political task of reducing emissions.

\section{Acknowledgments}

This paper is supported by the National Natural Science Foundation of China (Grant No.71964022).

\section{Declaration of Competing Interest}

We declare that we do not have any commercial or associative interest that represents a conflict of interest in connection with the work submitted.

Appendix A. Matrix of correlation coefficients of variables

\begin{tabular}{|c|c|c|c|c|c|c|c|c|c|c|}
\hline & $\begin{array}{c}\text { Brent } \\
\text { Crude } \\
\text { Oil CFD }\end{array}$ & $\begin{array}{c}\text { Bohai-Rim } \\
\text { Steam-Coal } \\
\text { Price Index }\end{array}$ & $\begin{array}{c}\text { Natural } \\
\text { Gas } \\
\text { Price }\end{array}$ & $\begin{array}{c}\text { SSE } \\
\text { Industrial } \\
\text { Index }\end{array}$ & $\begin{array}{c}\text { CSI } \\
300 \\
\text { Index }\end{array}$ & $\begin{array}{c}\text { Dow } \\
\text { Jones } \\
\text { Industrial } \\
\text { Average }\end{array}$ & $\begin{array}{c}\text { S\&P } \\
500 \\
\text { Index }\end{array}$ & $\begin{array}{c}\text { Tempera- } \\
\text { ture }\end{array}$ & $\begin{array}{c}\text { Air } \\
\text { Quality } \\
\text { Index }\end{array}$ & $\begin{array}{c}\text { Wind } \\
\text { Speed }\end{array}$ \\
\hline Brent Crude Oil CFD & 1.000 & 0.766 & -0.927 & 0.747 & -0.574 & 0.844 & 0.843 & 0.563 & -0.446 & -0.248 \\
\hline $\begin{array}{c}\text { Bohai-Rim Steam-Coal } \\
\text { Price Index }\end{array}$ & 0.766 & 1.000 & -0.867 & 0.928 & -0.544 & 0.802 & 0.865 & 0.027 & -0.671 & -0.459 \\
\hline Natural Gas Price & -0.927 & -0.867 & 1.000 & -0.797 & 0.555 & -0.829 & -0.829 & -0.424 & 0.585 & 0.200 \\
\hline SSE Industrial Index & 0.747 & 0.928 & -0.797 & 1.000 & -0.771 & 0.854 & 0.913 & 0.027 & -0.727 & -0.440 \\
\hline CSI 300 Index & -0.574 & -0.544 & 0.555 & -0.771 & 1.000 & -0.731 & -0.727 & -0.195 & 0.630 & 0.154 \\
\hline $\begin{array}{c}\text { Dow Jones } \\
\text { Industrial Average }\end{array}$ & 0.844 & 0.802 & -0.829 & 0.854 & -0.731 & 1.000 & 0.978 & 0.246 & -0.651 & -0.340 \\
\hline S\&P 500 Index & 0.843 & 0.865 & -0.829 & 0.913 & -0.727 & 0.978 & 1.000 & 0.165 & -0.637 & -0.409 \\
\hline Temperature & 0.563 & 0.027 & -0.424 & 0.027 & -0.195 & 0.246 & 0.165 & 1.000 & 0.112 & 0.110 \\
\hline Air Quality Index & -0.446 & -0.671 & 0.585 & -0.727 & 0.630 & -0.651 & -0.637 & 0.112 & 1.000 & 0.125 \\
\hline Wind Speed & -0.248 & -0.459 & 0.200 & -0.440 & 0.154 & -0.340 & -0.409 & 0.110 & 0.125 & 1.000 \\
\hline
\end{tabular}


Appendix B. The total variance contribution of each factor.

\begin{tabular}{|c|c|c|c|c|c|c|}
\hline \multirow{2}{*}{} & \multicolumn{3}{|c|}{ Initial eigenvalue } & \multicolumn{3}{c|}{ Square summation of loads extracted } \\
\cline { 2 - 7 } & Total & $\begin{array}{c}\text { Percentage } \\
\text { of variance }\end{array}$ & $\begin{array}{c}\text { Cumulative } \\
(\%)\end{array}$ & Total & $\begin{array}{c}\text { Percentage } \\
\text { of variance }\end{array}$ & $\begin{array}{c}\text { Cumulative } \\
(\%)\end{array}$ \\
\hline Brent Crude Oil CFD & 6.492 & 64.920 & 64.920 & 6.492 & 64.920 & 64.920 \\
\hline Bohai-Rim Steam-Coal Price Index & 1.439 & 14.395 & 79.315 & 1.439 & 14.395 & 79.315 \\
\hline Natural Gas Price & 0.958 & 9.576 & 88.891 & 0.958 & 9.576 & 88.891 \\
\hline SSE Industrial Index & 0.526 & 5.260 & 94.150 & & & \\
\hline CSI 300 Index & 0.290 & 2.899 & 97.049 & & & \\
\hline Dow Jones Industrial Average & 0.193 & 1.934 & 98.983 & & & \\
\hline S\&P 500 Index & 0.044 & 0.439 & 99.422 & & & \\
\hline Temperature & 0.038 & 0.381 & 99.804 & & & \\
\hline Air Quality Index & 0.013 & 0.132 & 99.936 & & & \\
\hline Wind Speed & 0.006 & 0.064 & 100.000 & & & \\
\hline
\end{tabular}

Appendix C. Comparison chart of percentile errors.

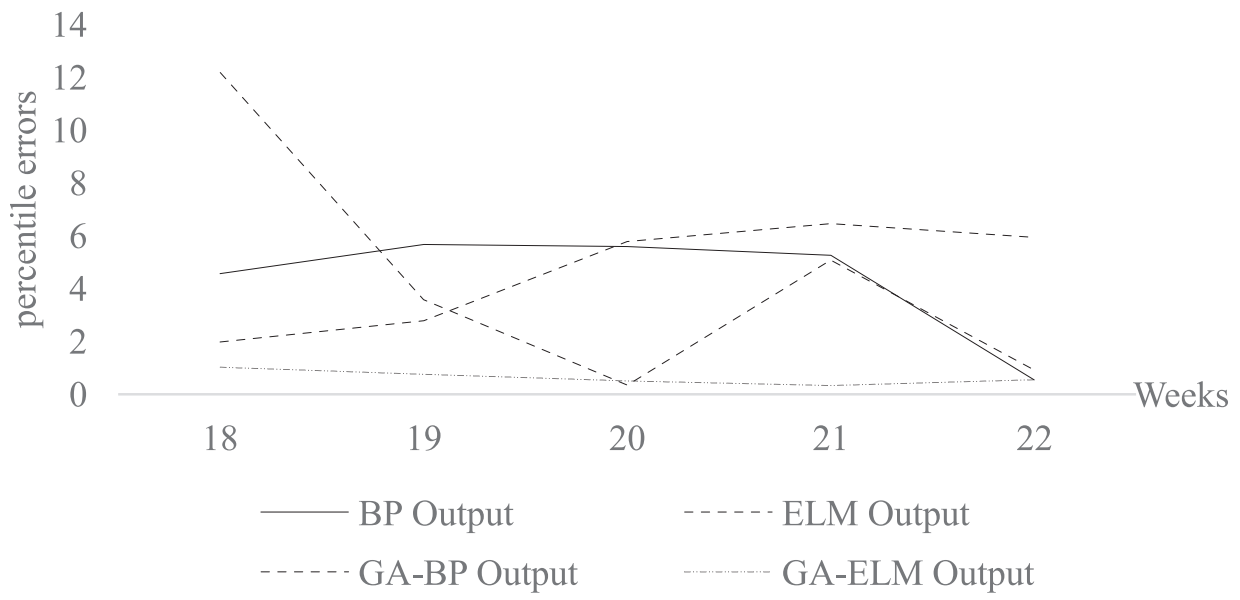

\section{References}

1. ZHU B.Z., WANG P., WEI Y.M. Multi-scale analysis of influencing factors of carbon market price based on EMD. Economic Perspectives. 92, 2012.

2. JIANG F., PENG Z.J. Forecasting of Carbon Price Based on BP Neural Network Optimized by Chaotic PSO Algorithm. Statistics \& Information Forum. 33, 93, 2018.

3. ZHANG J.J., DING L.L., SUN L.C. Research on enterprise carbon emission decision considering the substitution effect of stepped carbon tax and carbon trading. China population, resources and environment. 29, 41, 2019.

4. CHAI Q.M. Policy outlook on China's new goal of peaking carbon dioxide emissions and vision of carbon neutrality. World Environment. 20, 2021.

5. DONG Z.F., GE C.Z., HAO C.X., LONG F., CHENG C.Y., LI X.L. Environmental Economic Policy Annual Report 2019. Environmental Economy. 12, 2020.

6. LIU Y.F. Analysis on the Influencing Factors of China's Carbon Emissions Marke - Taking Guangzhou Carbon Emissions Exchange as An Example. China Forestry Economics. 79, 2021.

7. LIU C.L., LI Z.Y., GONG Y.Z. Research on Influencing Factors of Carbon Emission in China Based on
Nonparametric Model. Journal of Nanjing Xiaozhuang University. 36, 76, 2020.

8. DU Z.P., LIU F.C. Impacts on the Price of Regional Carbon Emissions Based on GA-BP-MIV Model. Price:Theory \& Practice. 42, 2018.

9. LIU J.Y., YANG F.J., LI Y.B. Research on Long-term Factors Affecting the Price Fluctuation of China's Carbon Emission Rights Trading - Based on the Carbon Price of Beijing Environmental Exchange. Statistical Theory and Practice. 11, 2020.

10. PENG W.Y., CHEN S.Y. Analysis and Forecast of Carbon Trading Price in China's Carbon Emission Pilot Market. Journal of Technology Economics. 39, 102, 2020.

11. XIN J., ZHAO C.Y. The Volatility Analysis of Chinese Carbon Trading Market - Based on the MS-VAR Model. Soft Science. 32, 134, 2018.

12. FANG C.H., MA T.J. Technology adoption with carbon emission trading mechanism: modeling with heterogeneous agents and uncertain carbon price. Ann. Oper. Res. 300, 2021.

13. MIN L., YANG W., XING W. Impact of China carbon emissions trading mechanism on industrial competitiveness: Evidence from Beijing. IOP Conference Series: Earth and Environmental Science. 657, 2021. 
14. QING Z. Research on the Impact of Carbon Emission Trading Mechanism on Power Industry Based on SWOT Analysis. Journal of Applied Science and Engineering Innovation. 6, 2019.

15. MANSANET-BATALLER M., PARDO A.,VALOR E. $\mathrm{CO}_{2}$ Prices, Energy and Weather. The Energy Journal. 28, 2007.

16. Alberola E., CHEVAllieR J., CHÈZE B. Price drivers and structural breaks in European carbon prices 2005-2007. Energy Policy. 36, 2007.

17. AlBEROLA E., CHEVAlliER J., CHÈZE B. Emissions Compliances and Carbon Prices under the EU ETS: A Country Specific Analysis of Industrial Sectors. Journal of Policy Modeling. 31, 2008.

18. KEPPLER J. H., MANSANET-BATALLER M. Causalities between $\mathrm{CO}_{2}$, electricity, and other energy variables during phase I and phase II of the EU ETS. Energy Policy. 38, 2010.

19. CAO G.X., XU W. Multifractal features of EUA and CER futures markets by using multifractal detrended fluctuation analysis based on empirical model decomposition. Chaos, Solitons and Fractals: the interdisciplinary journal of Nonlinear Science, and Nonequilibrium and Complex Phenomena. 83, 2016.

20. OBERNDORFER U. EU Emission Allowances and the stock market: Evidence from the electricity industry. Ecol. Econ. 68, 2009.

21. CAO J.W., LIN Z.P., HUANG G.B., LIU N. A model of carbon price interactions with macroeconomic and energy dynamics. Energy Economics. 33, 2011.

22. MANSANET-BATALLER M., CHEVALLIER J., HERVÉ-MIGNUCCI M., ALBEROLA E. EUA and SCER phase II price drivers: Unveiling the reasons for the existence of the EUA-sCER spread. Energy Policy. 39, 2011.

23. XU L., DENG S.J., THOMAS V. M. Carbon emission permit price volatility reduction through financial options. Energy Economics. 53, 2016.

24. KOCH N., FUSS S., GROSJEAN G., EDENHOFER O. Causes of the EU ETS price drop: Recession, CDM, renewable policies or a bit of everything? - New evidence. Energy Policy. 73, 2014.

25. CETIN M. A Change in the Amount of $\mathrm{CO}_{2}$ at the Center of the Examination Halls: Case Study of Turkey. Studies on Ethno-Medicine. 10:2, 146, 2017.

26. CETIN M., SEVIK H., SAAT A. Indoor air quality: The samples of Safranbolu Bulak Mencilis cave. Fresen. Environ. Bull. 26 (10), 5965, 2017.

27. CETIN M.,SEVIK H. Change of air quality in kastamonu city in terms of particulate matter and $\mathrm{CO}_{2}$ amount. Oxidation Communications. No 4-II, 3394, 2016.

28. CHEN X.H., WANG Z.Y. Empirical Research on Price Impact Factor of Carbon Emission Exchange: Evidence from EU ETS. Systems Eng. 30, 53, 2012.

29. WANG Z.H., HU Y. An Empirical Analysis of the Factors Affecting the Carbon Price in China. Journal of Industrial Technological Economics. 37, 128, 2018.

30. ZHAO L.X., HU C. Research on the Influencing Factors of my country's Carbon Emissions Trading Price - Empirical Analysis Based on Structural Equation Model. Price: Theory \& Practice. 101-104, 2016.

31. FENG Z.H., WEI Y.M. Systematic risk and Expectations of Returns in EU Carbon Market. Chinese Journal of Management. 8, 451, 2011.
32. GAO Y., GUO K. The Global Carbon Trading Market and Price Characteristics - Research on EU ETS. Studies of International Finance. 82-88, 2012.

33. PAOLELLA M.S., TASCHINI L. An econometric analysis of emission allowance prices. Journal of Banking and Finance. 32, 2008

34. BYUN S.J., CHO H. Forecasting carbon futures volatility using GARCH models with energy volatilities. Energy Economics. 40, 2013.

35. ZHU B.Z., WEI Y.M. Carbon price forecasting with a novel hybrid ARIMA and least squares support vector machines methodology. Omega. 41, 2013.

36. AROURI M.E.H., JAWADI F., Duc Khuong Nguyen. Nonlinearities in carbon spot-futures price relationships during Phase II of the EU ETS. Economic Modelling. 29, 2012.

37. WANG N. Forecasting of Carbon Price Based on BoostingARMA Model. StaStatistics \& Information Forum. 32, 28, 2017.

38. JI Q.H., SUN Y.Z., YU H., GUO X.F., SUN Y.P.,LIU Q. Study on forecast model of carbon emission quota price based on multiple linear regression analysis. Modern Chemical Industry. 38, 220, 2018.

39. EVA B., STEFAN T. Modeling the price dynamics of $\mathrm{CO}_{2}$ emission allowances. Energy Economics. 31, 2008.

40. BREDIN D., MUCKLEY C. An emerging equilibrium in the EU emissions trading scheme. Energy Economics. 33, 2011.

41. TSAI M.T., KUO Y.T. Application of Radial Basis Function Neural Network for Carbon Price Forecasting. Applied Mechanics and Materials. 3276, 2014.

42. LI W., LU C. The research on setting a unified interval of carbon price benchmark in the national carbon trading market of China. Appl. Energ. 155, 2015.

43. CUI H.Y., DOU X.S. Carbon Price Forecasts in Chinese Carbon Trading Market Based on EMD-GA-BP and EMDPSO-LSSVM. Operations Research and Management Science. 27, 133, 2018.

44. ZHANG C., HU B.B. Expectation of Multiple Factors BP International Carbon Market Price based on Error Correction. Prices Monthly. 11-18, 2017.

45. ZHU B.Z., WEI Y.M. Carbon price prediction based on integration pf GMDH, particle swarm optimization and least support vector machines. Systems EngineeringTheory \& Practice. 31, 2264-2271, 2011.

46. HUANG G., ZHU Q.Y., SIEW C.K. Extreme learning machine: Theory and applications. Neurocomputing. 70, 2005.

47. GENG Z.Q., DONG J.G., CHEN J., HAN Y.M. A new Self-Organizing Extreme Learning Machine soft sensor model and its applications in complicated chemical processes. Eng. Appl. Artif. Intel. 62, 2017.

48. HUANG G., DING X.J., ZHOU H.M. Optimization method based extreme learning machine for classification. Neurocomputing. 74, 2010.

49. CAO J.W., LIN Z.P., HUANG G.B., LIU N. Voting based extreme learning machine. Inform. Sciences. 185, 2011.

50. WANG K.K., DONG D.X., ZHEN H., SUN L.J., XU X.M. Forecast of Carbon Emissions in China Based on WOAELM Model. Ecological Economy. 36, 20, 2020.

51. ZONG W.W., HUANG G.B., CHEN Y.Q. Weighted extreme learning machine for imbalance learning. Neurocomputing. 101, 2013. 